\title{
O Batismo de crianças adotadas por pessoas do mesmo sexo (Parte I) ${ }^{1}$
}

\author{
The Baptism of children adopted by people of the same sex \\ (Part I)
}

\section{Marcio Fernando França ${ }^{2}$}

Resumo: A prática de batizar crianças é uma tradição imemorial da Igreja. Atualmente, se impõe um novo problema: o Batismo de crianças adotadas por pessoas do mesmo sexo. O respeito e a condenação das injustiças não se põem em discussão. Não obstante, estas ações não equivalem a uma legitimação da conduta homossexual, nem tampouco o reconhecimento de um direito ao matrimônio e, consequentemente, a equiparação de tal união à família e o direito de adotar crianças, por serem contrários ao direito natural. Não obstante o problema moral, é em razão do Batismo, e não de qualquer condição jurídica civil, que os conviventes fiéis têm responsabilidades de fé com as crianças colocadas sob seus cuidados. A capacidade de receber o Batismo (cf. can. 864) não deve ser condi-
Abstract: The practice of baptizing children is an immemorial tradition of the Church. Today, a new problem is imposed: the baptism of children adopted by people of the same sex. The respect and condemnation of injustices are not in dispute. Nevertheless, these actions do not amount to legitimizing homosexual conduct, nor do they amount to recognizing the right to marry and, consequently, to equating such a union with the family and the right to adopt children, because they are contrary to natural law. Despite the moral problem, it is because of Baptism, and not because of any civil legal condition, that the faithful cohabitants have responsibilities of faith with the children placed under their care. The ability to receive Baptism (cf. can. 864) should not be

1 Artigo dividido em duas partes. Na primeira parte tratamos das razões que justificam a concessão do Batismo à criança adotada. A segunda parte se ocupará da prática, das indicações pastorais à luz do Direito eclesial, sobretudo, do acompanhamento personalizado e das garantias da educação cristã da criança.

2 Presbítero da Arquidiocese de Londrina - PR. Graduado em Filosofia pelo Instituto Filosófico de Apucarana - PR e Bacharel em Teologia pela Pontifícia Universidade Católica do Paraná (PUCPR). Mestre em Direito Canônico pelo Pontifício Instituto de Direito Canônico do Rio de Janeiro - Extensão Londrina - e Doutorando em Direito Canônico pela Pontifícia Universidade Gregoriana de Roma - Itália. E-mail: <marcio.ffranca@hotmail.com> 
cionada pelas situações subjetivas humanas de outros. Nesse caso, o que fazer concretamente? Deve-se ou não batizálas? A resposta mais lógica é aquela já nos dada pelo Magistério da Igreja: administrar o Batismo sim - a reconfirmação de não privar as crianças de ascender às fontes da graça -, mas com a condição de que a educação católica da criança possa ser assegurada (fundada esperança).

Palavras chave: Batismo de criança, homossexualidade, matrimônio, adoção, fundada esperança. conditioned by the subjective human situations of others. In that case, what should be done concretely? Should they be baptized or not? The most logical answer is that already given to us by the Magisterium of the Church: to administer baptism yes - the reconfirmation of not depriving children of ascending to the sources of grace - but on the condition that the Catholic education of the child can be assured (founded hope).

Keywords: Baptism of a child, homosexuality, marriage, adoption, founded hope.

\section{Introdução}

A finalidade das páginas que se seguem é precisamente responder a seguinte interrogação: pode-se batizar crianças adotadas legalmente por pessoas do mesmo sexo, conviventes em união civil ou não, quando solicitarem o sacramento? A arguição suscita uma série de questionamentos que colocam em dúvida a possibilidade de se administrar o sacramento, o qual o Direito canônico também é chamado a acompanhar e responder.

O problema das uniões de pessoas do mesmo sexo e, consequentemente, o direito de adoção, têm ganhado cada vez mais espaço na sociedade. Como resultado, essas inovações têm gerado dúvidas e problemas na ação pastoral da Igreja, especialmente no que concerne à administração do Batismo às crianças no seio dessas uniões.

No Instrumentum laboris da III Assembleia Geral Extraordinária do Sínodo dos Bispos sobre a família (26 jun. 2014), levantou-se a questão acerca da transmissão da fé às crianças em uniões homoafetivas. Das respostas das Conferências episcopais resulta que seria mais útil receber diretrizes pastorais mais concretas para estas situações. A partir da leitura do documento dá-se a entender uma abertura a administração do Batismo, mas o mérito precisa ser aprofundado.

A questão abordada neste artigo abrange apenas as crianças, ou seja, os menores, antes dos sete anos completos (cf. can. 97 §2). É cer- 
to que o Código estabelece os requisitos para o Batismo infantil, mas é preciso elucidar a forma de proceder quando se tratar de crianças adotadas por pessoas do mesmo sexo. O objetivo é alcançar uma resposta favorável, da qual possam se valer clérigos e leigos, auxiliando-os na reflexão e ação pastoral em benefício da salus animarum.

\section{Sobre a equiparação das uniões homoafetivas ao matrimônio}

Nas últimas décadas, as reivindicações homossexuais ampliaram-se através de imposições ideológicas exercidas por influentes grupos de pressão que procuraram dar à homossexualidade um status social, não apenas de facto, mas também de iure. O Parlamento Europeu por meio da Resolução matrimônio, família e uniões homossexuais (08 fev. 1984), recomendou aos Estados membros admitirem a união homossexual como legítima forma conjugal e reconhecerem o direito à paternidade-maternidade ${ }^{3}$.

Tais atitudes e imposições tornaram-se um fenômeno moral e social preocupante principalmente nos países onde as uniões homoafetivas são estabelecidas com pretensão de pleno sustento e reconhecimento jurídico, chegando mesmo a favorecer a equivalência legal ao matrimônio propriamente dito - entre um homem e uma mulher, através de um contrato de união civil - e à família ${ }^{4}$.

No tocante a esta questão, o Papa Francisco na Exortação Apostólica Amoris Laetitia, ao tratar de algumas situações complexas, retoma a doutrina do Magistério:

"Quanto aos projetos de equiparação ao matrimônio de
uniões entre pessoas homossexuais, [...] não existe funda-
mento algum para assimilar ou estabelecer analogias, nem
sequer remotas, entre as uniões homossexuais e o desígnio
de Deus sobre o matrimônio e a família". É "totalmente

3 Cf. A. POLAINO-LORENTE, «"Matrimônio” de homossexuais», 610.

4 Cf. CONGREGAÇÃo PARA A EdUCAÇÃO CATÓLICA, Homem e mulher os criou, 14; CONGREGATIO PRO DOCTRINA FIDEI, De contubernalibus eiusdem sexus quoad consectaria contubernii, 1; FRANCISCUS, Adhortatio Apostolica Post-Synodalis Amoris Laetitia, 251; SínODO DOS BisPOS, Instrumentum laboris, 110-112. 
inaceitável que as Igrejas locais sofram pressões nesta matéria, e que os organismos internacionais condicionem as ajudas financeiras aos países pobres à introdução de leis que instituam o 'casamento' entre pessoas do mesmo sexo"s.

Do ponto de vista teológico, a diferença sexual pertence à ordem natural estabelecida na criação. Segundo o livro do Gênesis, Deus criou o homem à sua imagem e semelhança, como varão e mulher (cf. Gn 1, 27). Ambos são criados em idêntica dignidade e em perfeita igualdade enquanto pessoas e complementares em seu ser respectivo de homem e de mulher. A negação da dualidade de homem e mulher como um dado da criação, faz com que a família também deixe de existir como realidade pré-estabelecida pela criação ${ }^{6}$.

Nenhuma ideologia pode cancelar do espírito humano a certeza de que o matrimônio só pode existir absolutamente entre duas pessoas de sexo diferente. Do contrário, o pacto matrimonial torna-se uma realidade impossível, por causa da retirada da primeira das suas condições, a qual estabelece que os contraentes sejam personas iure habiles (cf. can. $1057 \S 1$ ), ou seja, um homem e uma mulher ${ }^{7}$.

Com a crescente secularização da sociedade e do individualismo exagerado desvirtuando os vínculos familiares, "[o] matrimônio tende a ser visto como mera forma de gratificação afetiva, que se pode constituir de qualquer maneira e modificar-se de acordo com a sensibilidade de cada um" ". Apesar desta realidade, o vínculo matrimonial e a estrutura familiar não são elementos meramente transitórios e estranhos à natureza, mas continuam ser, não obstante o passar do tempo e numerosas teorias, uma realidade viva do casal, pais e filhos.

Não tem sentido reconhecer o título de cônjuges a dois indivíduos do mesmo sexo, unidos por vínculos inequívocos, a requererem

5 Franciscus, Adhortatio Apostolica Post-Synodalis Amoris Laetitia, 251.

6 Cf. CONGREGAÇão PARA A EDUCAÇÃo CATÓlICA, Homem e mulher os criou, 34; Jỗo PAUlo II, Catecismo da Igreja Católica, 369-372.

7 Cf. CONGREgAtio PRO DOCTRINA FIDEI, De contubernalibus eiusdem sexus quoad consectaria contubernii, 2; IOANNES PAULUS II, Allocutio Ad Romanae Rotae praelatos auditores, 622-627.

8 Franciscus, Adhortatio Apostolica Evangelii Gaudium, 66. 
um reconhecimento público da sua união. Tal pretensão é um grave sinal da deterioração da consciência moral social. Sem dúvida, esse modo de agir deriva da falta de um exame atencioso da identidade, da natureza e das características dessas pessoas por parte dos legisladores, além do próprio matrimônio com o qual essa união quer equiparar-se.

As características do matrimônio entre um homem e uma mulher não se verificam nas relações homossexuais, "por mais que a segunda tome a primeira como 'analogatum princeps' e nela se inspire, procurando, sem dúvida, igualar-se a ela"9. Essas inovações acarretam grandes desafios à ação pastoral da Igreja, suscitando interrogações sobre o bem integral da pessoa humana, de modo particular das crianças no seio destas uniões, especialmente no que tange a transmissão da fé.

\section{Adoção como consequências da equiparação}

Ao longo da história a adoção passou por uma profunda evolução: do sentido político no direito romano clássico, passando pela finalidade sucessória durante a Idade Média, até tornar-se a partir do século XX, uma instituição de proteção de menores abandonados, equiparada à filiação com os mesmos direitos e deveres. Consequentemente, a filiação deixou de ser um vínculo jurídico proveniente de um vínculo biológico, para sê-lo a partir de uma decisão legal, sujeita a formalidades legais e judiciais ${ }^{10}$.

No Direito canônico não existe uma normativa especial sobre as condições e a forma de adoção. Define apenas que "[os] filhos que tenham sido adotados de acordo com a lei civil são considerados filhos daquele ou daqueles que os adotaram" (can. 110), ou seja, reconhece como válido, para os efeitos canônicos, o parentesco legal que surge da adoção realizada em conformidade com o Direito civil. A expressão "de acordo com a lei civil" - qui ad normam legis civilis - supõe a canonização da normativa civil e sua correspondente interpretação

\footnotetext{
9 A. Polaino-Lorente, «"Matrimônio” de homossexuais», 611.

10 Cf. M.H. DinIZ, Curso de Direito civil brasileiro, 567-568.
} 
com o objetivo de responder, neste caso, às necessidades práticas da vida da Igreja.

$\mathrm{O}$ can. 22 adverte que as leis civis às quais a lei canônica remete, deve operar no ordenamento canônico com os mesmos efeitos iisdem cum effectibus serventur - do ordenamento civil. Há um reconhecimento formal do Direito estatal como fonte subsidiária do Direito canônico para os casos expressamente invocados pelo legislador. Desse modo, a adoção civil produz no ordenamento canônico, os efeitos decorrentes da patria potestas entre o adotante - ou adotantes - e o adotado.

Em contrapartida, as reivindicações das pessoas homossexuais, em especial dos conviventes, chegaram ao ponto de reivindicar o direito à adoção de crianças, o que têm gerado dúvidas e problemas na ação pastoral da Igreja. Esta situação inclui, efetivamente ou potencialmente:

[1] "A união livre" entre membros do mesmo sexo, que procuram adotar uma criança ou ter uma própria através da inseminação artificial assistida, a fecundação in vitro ou a maternidade "substitutiva". [2] "Matrimônios" entre pessoas do mesmo sexo, reconhecidos pelo Direito civil, cujos componentes buscam adotar uma criança ou ter uma própria, através da inseminação assistida, a fecundação in vitro ou a maternidade "substitutiva"11.

Onde tais reivindicações constituem um direito de fato é evidente o caráter ambíguo e polissêmico de vários termos. Assim, dois indivíduos do mesmo sexo que convivem de maneira estável são chamados de casais. Ao serem autorizados à adoção, são designados como pais ou mães dos adotados, que, por sua vez, são considerados filhos daqueles que os adotaram. Por fim, este novo instituto civil é qualificado como uma nova modalidade de família ${ }^{12}$.

11 J. HAGAN, «Novos modelos de família», 745.

12 Cf. J.F. FALCÃO DE BARRos, Os sacramentos da Iniciação cristã, 3; J. HAGAN, «Novos modelos de família», 745. 
Estes termos, usados indistintamente, não correspondem ao seu significado original: para a Igreja duas pessoas homossexuais "não são [um casal], sua convivência não é matrimônio, ambos não constituem família e não são pais das crianças adotadas"13. O estabelecimento de vínculos de filiação entre um menor e dois homens ou duas mulheres não corresponde nem ao Direito natural nem ao conceito de filiação estabelecido pelo Direito canônico positivo.

Para A. Polaino-Lorente "[a] finalidade da adoção é a proteção do menor e não a satisfação do adulto sem descendência"14. O desejo de maternidade ou paternidade não produz nenhum tipo de direito: "o filho não pode ser considerado como objeto de propriedade, a que conduziria o reconhecimento de um pretenso 'direito ao filho""15. Pelo contrário, são incontestáveis os direitos da criança de ter uma família fundada sobre o matrimônio e a complementaridade das duas figuras paterna e materna. Em suma, adoptio imitat naturam $^{16}$.

No entanto, a lei canonizada pode ser interpretada e aplicada com os mesmos efeitos - iidem cum effectibus - do seu ordenamento de origem - continua o can. 22 - "desde que não sejam contrárias ao Direito divino e não seja determinado o contrário pelo Direito canônico". Diante das mudanças no regime jurídico de adoção de vários países, torna-se necessário rever a posição do Direito canônico sobre esta matéria. Diante da obstinação dos episódios legislativos aludidos e suas consequências, não é possível uma interpretação literal do can. 110 .

Das poucas normas contidas no Código atual (cf. cann. 110; 535 $\S 2 ; 877 \S 3 ; 1094)$, no can. 1094, a palavra adoção aparece no contexto do matrimônio e só a partir deste é compreendida. O can. 17 estabelece que "as leis eclesiásticas devem ser entendidas segundo o sentido próprio das palavras, considerado no texto e no contexto". Desse modo, conclui-se que uma filiação de origem adotiva e equiparada à consanguínea a favor de dois homens ou de duas mulheres está sujeita aos

13 J.F. FAlCÃo DE BARRos, Os sacramentos da Iniciação cristã, 4.

14 A. POLAINO-LORENTE, «"Matrimônio" de homossexuais», 620.

15 Jỗo Paulo II, Catecismo da Igreja Católica, 2378.

16 Cf. A. Polaino-Lorente, "“Matrimônio" de homossexuais», 620; CongregAÇÃO PARA A EDUCAÇÃO CATÓlICA, Homem e mulher os criou, 38; CONGREGATIO PRO DOCTRINA FIDEI, Instructio De observantia erga vitam humanam nascentem deque procreationis dignitate tuenda, II, A, 1 . 
limites estabelecidos pelo can. 22, ou seja, não pode ser observada com os mesmos efeitos por ser contrária ao ius divinum ${ }^{17}$.

No entanto, o can. 22 interpretado contrario sensu, não impõe a inobservância das leis civis contrárias ao Direito divino ou canônico criando uma espécie de lacuna no ordenamento jurídico eclesial em matéria de adoção - mas a sua observância com efeitos distintos, mas sempre em conformidade com o Direito canônico. Na prática, a remissão será parcial: a canonização da lei civil permitirá aplicar o can. 110 e reconhecer os efeitos canônicos somente àquelas adoções que não contrariem as condições estabelecidas pelo legislador ${ }^{18}$.

\section{Caridade e Verdade em relação às pessoas homossexuais}

A Sagrada Escritura determina realizar a Verdade na Caridade (cf. Ef 4, 15; 1Cor 13, 6). Fiel à Palavra do Senhor, a Igreja coloca-se a serviço de cada homem, mulher e criança, com misericordiosa solicitude pastoral (cf. $L c 6,36$ ), para que "todos sejam salvos e cheguem ao conhecimento da verdade" (1Tm 2, 4). Com ânimo materno sobre estes filhos seus, a Igreja ensina que a pessoa homossexual deve ser plenamente respeitada na sua dignidade humana, acolhida com respeito e encorajada a seguir o plano de Deus com um empenho particular no exercício da castidade ${ }^{19}$.

Constata-se o quão essas pessoas têm sido, e muitas vezes são ainda, objeto de desprezo, ódio e até mesmo de ação violência em alguns setores da sociedade. Às vezes esse ódio é claramente manifesto; outras vezes, é mascarado e dá origem a formas mais dissimuladas de ódio. Qualquer forma de discriminação, violência ou agressão são dignas de condenação por parte dos pastores da Igreja. A dignidade

17 Cf. J. OTADUY, «Comentario al can. 22», 415.

18 Cf. J.N. VALLE, «Adopción», 254.

19 Cf. Franciscus, Adhortatio Apostolica Post-Synodalis Amoris Laetitia, 250; Pontifício Conselho «Justiça E PAZ», Compêndio da Doutrina Social da Igreja, 139. Ver também Jỗo PAUlo II, Catecismo da Igreja Católica, 23572359. 
própria de cada pessoa deve ser respeitada sempre, nas palavras, nas ações e nas legislações ${ }^{20}$.

O respeito e a condenação das injustiças não se põem em discussão. Não obstante, estas ações não equivalem a uma legitimação da conduta homossexual, nem tampouco se reconhece um direito ao matrimônio com a consequente equiparação de tal união à família. $\mathrm{O}$ mesmo se aplica ao direito de adoção: a não legitimação tem o seu fundamento no direito da criança de crescer num ambiente o mais próximo possível da família natural, ou seja, constituído pelo pai e pela mãe adotivos, com relação estável, capaz de favorecer o seu crescimento e desenvolvimento ${ }^{21}$.

Para a Igreja "a sexualidade humana é, portanto, um Bem: parte daquele dom criado que Deus viu ser 'muito bom' quando criou a pessoa humana à sua imagem e semelhança e 'homem e mulher os criou' $(G n 1,27)^{, 22}$. O propósito do desejo sexual é unir o homem à mulher pelo vínculo do matrimônio aberto para geração de nova vida: "[a] complementaridade fisiológica, baseada na diferença sexual, assegura as condições necessárias para a procriação"23.

Torna-se frequente a acusação de preconceito ou fundamentalismo religioso àqueles que se posicionam contrários. Qualquer reflexão crítica sobre o assunto é sinônimo de ofensa, chegando ser equiparada a um delito. É preciso ajudá-los para não serem levados a crer que as suas relações sejam uma opção moralmente aceitável.

Recordar a verdade fundamental sobre o significado autêntico da sexualidade humana e do amor conjugal no plano divino não supõe discriminação nem ofensa; pelo contrário, tal verdade é um bem essencial, uma forma de caridade eminente e fator de autêntica liberta-

20 Cf. CONGREGATIO PRO DOCTRINA FIDEI, Epistola Ad universos catholicae Ecclesiae episcopos de pastorali personarum homosexualium cura, 10.

21 Cf. A. Polaino-Lorente, "“Matrimônio" de homossexuais», 620; PONTIFício CONSElHO PARA A FAMÍlia, Família, matrimônio e uniões de fato, 49.

22 PONTIFÍCIO CONSELHO PARA A FAMíliA, Sexualidade humana, 11.

23 CONGREGAÇÃo PARA A EdUCAÇÃo CATÓLICA, Homem e mulher os criou, 28. 
ção das pessoas ao qual elucida que o vínculo entre duas pessoas do mesmo sexo não pode constituir uma verdadeira família ${ }^{24}$.

É necessário promover um programa pastoral autêntico, plenamente concorde com o ensinamento da Igreja, onde as pessoas homossexuais possam receber - em todos os níveis da vida espiritual - os auxílios que necessitam e aos quais têm direito. O zelo pastoral dos ministros e dos agentes pastorais deve inspirar atitudes de aproximação e ajuda concreta.

Desta forma, a comunidade cristã na sua totalidade pode chegar a reconhecer sua vocação de assistir estes seus irmãos e irmãs, superando o grande desafio de desenvolver "uma pastoral que consiga manter o justo equilíbrio entre acolhimento misericordioso dessas pessoas e acompanhamento gradual rumo a uma autêntica maturidade humana e cristã" ${ }^{25}$, sem exceções nem exclusões, afim de que elas vivam uma conversão a lhes restituir a alegria da fé e o desejo de se comprometerem com o Evangelho.

\section{Responsabilidade das pessoas homossexuais enquanto batizadas}

Para a legislação civil, os conviventes homossexuais são considerados responsáveis pelas crianças adotadas porque têm, em relação a elas, os mesmos direitos e deveres de pais. Em âmbito eclesiástico, tal analogia de paternidade-maternidade não é reconhecida. Deste modo, é adequado chamá-los de "responsáveis" tratando apenas da sua condição canônica enquanto batizados ${ }^{26}$.

Ao receber o sacramento do Batismo, toda pessoa torna-se christifidelis e é constituída persona in Ecclesiae, conforme os cann. $204 \S 1$ e 96. Desta condição jurídica nascem os direitos e deveres fundamentais enunciados nos cann. 208-223, garantindo aos fiéis a sua participação na vida e missão da Igreja.

24 Cf. United States Conference of CATHOlic Bishops, Ministerio a las personas con inclinación homosexual, 16; PONTIFÍCIO CONSELHO PARA A FAMÍLIA, Família, matrimônio e uniões de fato, 49.

25 SínODO DOS BISPOS, Instrumentum laboris, 118.

26 Cf. J.F. FALCÃo DE BARROS, Os sacramentos da iniciação cristã, 4. 
Como todos os fiéis, as pessoas homossexuais batizadas têm o direito de manifestar aos Pastores da Igreja "as próprias necessidades, principalmente espirituais, e os próprios anseios" (can. 212 §), para realização de sua vocação cristã e edificação de todo o Corpo Místico de Cristo. Por outro lado, os Pastores têm a obrigação de atendê-los com solicitude e amor paterno, sobretudo no que for necessário ou apropriado para realização de sua vocação. Obrigação destinada, em última análise, a facilitar o direito de receber os auxílios da Palavra de Deus e dos sacramentos (cf. can. 213; LG 37.42).

O CIC de 1917 falava simplesmente do direito dos leigos aos bens espirituais: "os leigos têm o direito a receber do clero, de acordo com a disciplina eclesiástica, os bens espirituais e especialmente os auxílios necessários para a salvação" (can. 682, CIC de 1917). No entanto, o Concílio Vaticano II marcou uma tomada de consciência mais profunda deste direito aplicando-o a todos os fiéis, passando do mínimo necessário para salvação para a recepção abundante dos bens espirituais que todo cristão necessita para seguir sua vocação a santidade.

Os Bispos, sendo os principais dispensadores dos mistérios de Cristo, devem esforçar-se continuamente para que os fiéis confiados a seus cuidados cresçam na graça mediante a celebração dos sacramentos (cf. can. 387). À mesma conclusão pode-se chegar ao ler o can. $528 \S 2$, referente à função do pároco que deve empenhar-se para que os fiéis se alimentem com a devota celebração dos sacramentos.

É evidente o advento de dúvidas e dificuldades quando duas pessoas do mesmo sexo, unidas por uma relação contrária aos ensinamentos da Igreja sobre o Matrimônio e a sexualidade, solicitam o Batismo para uma criança que se encontra sob seus cuidados. Não obstante o problema moral, os conviventes, enquanto fiéis são também responsáveis em "promover o crescimento da Igreja e sua contínua santificação" (can. 210; LG 33) ${ }^{27}$.

É óbvio que o direito ao Batismo não é próprio dos fiéis, mas precisamente daqueles que não o são. Não é fácil compreender como, não sendo ainda membro da Igreja, a pessoa se apresenta - no caso de crianças, estas são apresentas por seus pais ou responsáveis - como titular de um direito. Segundo o mandato de Cristo, o Evangelho deve

27 Cf. J.F. FALCÃO DE BARROS, Os sacramentos da iniciação cristã, 4-5. 
ser anunciado a toda criatura, e todos devem ser batizados, porque necessitam da salvação (cf. Mc 16, 15-16).

Somente é capaz de receber validamente o sacramento, dispõe o can. 864, todo ser humano vivo ainda não batizado - omnis et solus homo -, a fim de incorporar-se a Cristo e a sua Igreja e fazer parte do Povo de Deus. Em suma, o legislador tutela a capacidade universal para o Batismo fundada na vontade salvífica de Deus. É suficiente reiterar que o Batismo é um direito da pessoa e ninguém pode ser excluído, independente de raça, nacionalidade, condição, idade ou cultura ${ }^{28}$.

A capacidade de receber o Batismo, conforme determina o can. 864, não deve ser condicionada pelas situações subjetivas humanas de outros. Deve-se ter "em mente antes de tudo a salvação da criança, para que não lhe seja negado o benefício do sacramento" 29 . Neste caso, a conduta dos responsáveis não deve impedi-la de ascender às fontes da graça, pois "a criança não tem nenhuma responsabilidade pelo estado de vida de quem pede para ela o sacramento" 30 .

No ano de 2007, os Bispos Católicos dos Estados Unidos elaboraram as Diretrizes básicas para o ministério pastoral entre as pessoas com inclinação ou tendência homossexual. Quanto ao Batismo de crianças sob o cuidado de pares do mesmo sexo, a Conferência apresenta uma séria preocupação pastoral. No entanto, não nega o sacramento do Batismo a essas crianças, desde que haja uma fundada esperança de que elas serão educadas na religião católica ${ }^{31}$.

Na Exortação Apostólica Evangelii Gaudium, Papa Francisco exorta que a Igreja deve ser a casa aberta do Pai e, além das portas do templo, se considerasse com prudência e audácia não fechar outras portas, especialmente a porta do Batismo:

Todos podem participar de alguma forma na vida eclesial, todos podem fazer parte da comunidade, e nem sequer as portas dos sacramentos se deveriam fechar por uma razão

28 Cf. M. BLANCO, «Comentario al can. 489», 448.

Observações preliminares, n. 8. In: Ritual do Batismo de crianças.

30 CONFERÊNCIA NACIONAL DOS BISPOS DO BRASIL, Orientações pastorais e canônicas, 2.

31 Cf. United States Conference of CAtholic Bishops, Ministerio a las personas con inclinación homosexual, 23. 
qualquer. Isto vale, sobretudo, quando se trata daquele sacramento que é a "porta": o Batismo. [...] Muitas vezes agimos como controladores da graça e não como facilitadores. Mas a Igreja não é uma alfândega; é a casa paterna, onde há lugar para todos com a sua vida fadigosa ${ }^{32}$.

O Instrumentum laboris da III Assembleia Geral Extraordinária do Sínodo dos Bispos (26 jun. 2014), ao tratar da transmissão da fé às crianças adotadas por pessoas do mesmo sexo, apresenta alguns pontos significativos. Deve-se constatar - afirma o documento - que as respostas recebidas se pronunciam contra a adoção de crianças por parte de pessoas do mesmo sexo, porque veem em perigo o bem integral da criança, que tem direito a ter uma mãe e um pai. Todavia, destacam que, caso as pessoas que vivem nestas uniões peçam o Batismo à criança adotada, esta deve ser acolhida com a mesma ternura e solicitude que recebem as outras crianças ${ }^{33}$.

Apesar da solicitação de diretrizes pastorais mais concretas para estas situações, o caminho de discernimento apresentado para a realização do Batismo não apresenta nenhuma inovação em relação a prática já adotada pela Igreja:

É evidente que a Igreja tem o dever de averiguar as condições reais em vista da transmissão da fé [a criança]. Caso se alimentem dúvidas racionais sobre a capacidade efetiva de educar cristãmente [a criança] por parte de pessoas do mesmo sexo, deve garantir o apoio adequado - como de resto é exigido de qualquer outro casal que pede o batismo para os seus filhos. Neste sentido, uma ajuda poderia vir também de outras pessoas presentes no seu ambiente familiar e social. Nestes casos, a preparação para o eventual batismo [...] será particularmente cuidada pelo pároco,

32 Franciscus, Adhortatio Apostolica Evangelii Gaudium, 47.

33 Cf. SínOdo DOs BisPos, Instrumentum laboris, 120. 
também com uma atenção específica na escolha do padrinho e da madrinha ${ }^{34}$.

Embora não seja um direito absoluto, mas condicionado à devida preparação e disposições, os conviventes homossexuais, enquanto batizados, devem solicitar à Igreja a administração do batismo às crianças: "é em razão do Batismo, e não de qualquer condição jurídica civil, que os conviventes fiéis têm responsabilidades de fé com as crianças colocadas sob os seus cuidados" ${ }^{\text {35 }}$. Como membros da comunidade eclesial eles devem gerar estas criaturas para a vida dos filhos de Deus.

Além do mais, a solicitação do sacramento para a criança pode ser uma oportunidade na qual o pároco os anime a retomar a sua vida cristã em sua plenitude. No entanto, não parece apropriado condicionar o Batismo da criança a uma mudança de atitude dos responsáveis no seu modo de vida, no caso de haver uma fundada esperança de que a criança será educada de acordo com a fé católica.

\section{Condições para administração dos sacramentos em geral}

Entre os muitos motivos que levam os fiéis a procurar a Igreja, se destacam a solicitação dos "auxílios da Palavra de Deus e dos sacramentos" (can. 213), como parte daquele alimento espiritual necessário para receber a graça santificante de modo vivo e eficaz. $\mathrm{O}$ direito de receber os sacramentos encontra uma primeira regulamentação no can. $843 \S \S 1-2$.

O $§ 1$ estabelece, por um lado, o dever dos Pastores de dispensar os sacramentos e, por outro, as condições necessárias para o exercício do direito. Como consequência do direito dos fiéis de receberem os sacramentos - e dos não batizados ao Batismo - os Pastores têm o dever não somente de administrá-los quando se reúnem as condições

34 SínOdo DOS BisPos, Instrumentum laboris, 120. No texto, a palavra "filho" foi substituída propositalmente por "[criança]", para adequar o texto e evitar equívocos de interpretações.

35 J.F. FALCÃO DE BARROS, Os sacramentos da iniciação cristã, 5. 
exigidas, mas também de proporcionar os meios necessários, conforme $\S 2$, para que possam recebê-los de forma frutuosa.

Trata-se de um direito real, cujo exercício não há de entender-se em sentido absoluto, mas condicionado por três requisitos que podem afetar, dependendo do sacramento em questão, tanto a liceidade como a validade. Portanto, a primeira resposta será positiva, quer dizer, os sacramentos não serão negados ao requerente, mas celebrados quando observadas as condições exigidas pela lei: a) se o pedido é solicitado de modo oportuno; b) se estiver devidamente disposto a recebê-lo; c) se não estiver proibido de recebê-lo pelo Direito.

A oportunidade, as disposições e os impedimentos jurídicos são condições que justificam a celebração de um sacramento. Variam segundo a natureza e função de cada sacramento e são determinadas pelas normas particulares de cada um. Cabe fazer apenas algumas considerações gerais para todos os sacramentos, a saber:

\subsection{Oportunidade}

Pedir oportunamente significa cumprir certas condições relativas ao tempo, lugar ou modo de celebrar. Diante de pedidos estranhos por parte dos fiéis, o sacerdote deverá mostrar firmeza com o objetivo de preservar o sentido e a dignidade do sacramento, mostrando a inoportunidade ou inconveniência do pedido.

Normalmente o fiel solicita ao pastor próprio, isto é, ao pároco, ou aos seus colaboradores (vigário paroquial, capelão) que possuem a faculdade habitual de administrar os sacramentos. No entanto, pelo caráter público tanto do ministério sagrado como do direito aos sacramentos, qualquer ministro tem o dever de justiça de dispensá-los a quem se encontra em circunstâncias de grave dificuldade para acudir ao seu pastor próprio ou a outro (cf. can. $986 \S 2)^{36}$.

\subsection{Devida disposição}

No que diz respeito às devidas disposições, são aquelas condições do fiel que permitem a recepção válida, lícita e frutuosa dos sa-

36 Cf. J. SAN José PRISCO, Derecho parroquial, 180. 
cramentos. Pode considerar-se devidamente disposto aquele que tenha recebido a devida evangelização e instrução catequética e, conhecendo por tanto suas implicações, manifesta livremente o desejo de receber um sacramento.

Para os pastores que possuem cura de almas, a adequada preparação se converte em obrigação jurídica e moral; no caso do pároco se converte numa tarefa primordial. O ministro deve constatar, enquanto possível, que a pessoa reúna as condições necessárias. Caso contrário, deverá fazer o possível para colocá-la em condições de receber o sacramento em causa. Mas se não houver mudanças em suas disposições, o ministro pode e deve recusar o sacramento ${ }^{37}$.

\subsection{Ausência de proibição legal}

O último requisito para o exercício do direito aos sacramentos, e do consequente dever de administrá-los, exige que o solicitante não esteja impedido ou proibido de recebê-los, seja pelo Direito divino, natural ou positivo, seja pelo Direito eclesiástico. Os impedimentos e proibições legais que o Direito estabelece, têm por objetivo assegurar a validade e a liceidade do ato sacramental (cf. can. 841) ${ }^{38}$.

Contudo, aqueles sacramentos que em determinadas circunstâncias, sobretudo in periculo mortis, podem ser meio necessário para a salvação de uma pessoa, a Igreja não duvida em administrá-los, ao menos sub condicione, pressupondo a vontade do sujeito e suas disposições, e dispensando se é necessário de qualquer requisito ou impedimento que não esteja estritamente ligado à essência do sacramento em questão (cf. cann. 850; $861 \S 2 ; 865 \S 2 ; 961 ; 976 ; 1005$ ).

37 Cf. J. SAN JosÉ PRISCO, Derecho parroquial, 180.

38 Exemplos de proibições: cann. 1331-1332 (excomunhão, suspensão, interdito; cf. também o can. 915); cann. 1083-1107 (impedimentos para o matrimônio); can. 977 (proibição de absolver o cúmplice do pecado contra o sexto mandamento); can. 844 (proibição de dar os sacramentos àqueles que não estão em plena comunhão com a Igreja Católica, a não ser nas condições previstas pelo dito cânone); cann. 1040-1042; 1044 (irregularidade e impedimentos acerca do sacramento da ordem). 


\section{Condições para a realização do Batismo de crianças}

Os cann. 867-868 tratam especificamente das condições para realização do Batismo de crianças. A normativa apresenta esta prática como sendo um dever legítimo, por se tratar de uma praxe constante da Igreja no decurso dos séculos. Excetuado o perigo de morte, caso em que o Batismo deve ser administrado sem demora - sine ulla mora (cf. can. 867 §) -, veremos que a Igreja não admite sua realização sem o consentimento dos pais e a garantia da educação na fé católica (cf. can. $868 \S 1$ ).

\subsection{O direito-dever de pedir o Batismo para a criança}

Batizar os filhos o quanto antes é um direito-dever fundamental dos pais, "que não poderá ser limitado ou restringido por uma lei particular; ou, quanto menos, por uma norma de alcance inferior ao próprio $C I C, 39$. O can. $867 \S 1$ reafirma a disciplina em favor do Batismo infantil, exortando que seja realizado quam primum após o nascimento da criança, com a consequente obrigação dos pais de se dirigirem ao pároco a fim de pedir o sacramento para o filho e ser devidamente preparados.

O pedido pode ser feito logo depois do nascimento, ou mesmo antes. Como a criança ainda não é capaz deste ato, pertence aos pais ou aos que os substituem desempenhar esta missão ${ }^{40}$. O CIC de 1917 não mencionava expressamente o papel dos pais em pedir o Batismo para os filhos, apenas prescrevia que a criança fosse batizada quamprimum, reprovando seu atraso para além de três a oito dias após o nascimento (cf. can. 770, CIC 1917). No Código atual, esta expressão significa nas primeiras semanas após o nascimento; no Código oriental significa de acordo com os costumes legítimos (cf. can. $686 \S 1$, CCEO).

Embora não possam substituir a vontade dos filhos, os pais exercem um papel importante quanto à sua participação na vida sacramental. Ainda que a liberdade de escolha da própria religião seja

39 M. BLANCO, «Comentario al can. 867», 485.

40 Cf. M.F. SousA E SILVA, Direito Sacramental, 59. 
um direito pessoal, esta poderá ser antecipada para o benefício espiritual da criança, desde que ela não tenha atingido o uso da razão. Quanto à preparação, o pároco, por si ou por outros, deve cuidar que os pais sejam devidamente instruídos por meio de uma preparação catequético-espiritual adequada (cf. cann. $867 \S 1 ; 851,2^{\circ}$ ). Esta preparação está em íntima conexão com a obrigação de pais e padrinhos de educar cristãmente seus filhos.

Em relação ao tempo para realização do Batismo, deve-se ressaltar que a devida preparação não há de implicar atrasos na administração do sacramento, a não ser que por graves razões de ordem pastoral, poderá se determinar um período de espera mais longo. O Ritual do Batismo de crianças determina as seguintes circunstâncias para sua fixação: a) a saúde da criança, a fim de que não seja privada do sacramento; b) a saúde da mãe, de modo que possa estar presente, sempre que possível; c) a necessidade pastoral, isto é, o tempo necessário de preparação dos pais e da celebração ${ }^{41}$.

Observa-se que o Batismo celebrado nas primeiras semanas de vida é possível quando a criança vive num ambiente onde a fé cristã é testemunhada. Não é raro o caso de pais que, embora pedindo o Batismo para seus filhos, vivem fora de qualquer prática cristã. Neste caso, deve-se levar em consideração as orientações contidas na Instrução sobre o Batismo de crianças, da Sagrada Congregação para a Doutrina da Fé ${ }^{42}$.

Por último, é importante recordar o objeto da discussão: as crianças adotadas por pessoas do mesmo sexo. Que fazer concretamente? Deve-se ou não batizá-las? A resposta mais lógica é aquela já nos dada pelo Magistério da Igreja: administrar o Batismo sim, mas com a condição de que a educação cristã da criança possa ser assegurada.

\subsection{Condições para validade e a liceidade do Batismo}

Para a válida administração do Batismo é preciso observar os elementos necessários estabelecidos pela Autoridade Suprema: a) ma-

41 Cf. Observações preliminares, 8. In: Ritual do Batismo de crianças.

42 Cf. SACRA CONGREGATIO PRO DOCTRINA FIDEI, Instructio De Baptismo parvulorum, 27-33. 
téria: água verdadeira (cf. cann. 849; 853); b) forma verbal: N... Eu te batizo, em nome do Pai e do Filho e do Espírito Santo (cf. cann. 846 $\S 1 ; 849 ; 853)$; c) intenção de fazer o que a Igreja faz ${ }^{43}$.

Quanto ao sujeito, é capaz de receber o Batismo validamente toda pessoa não batizada e somente ela (cf. can. 864). Portanto, é plenamente legítimo, até mesmo um dever, batizar as crianças. Agora, para ser batizada licitamente, o can. $868 \S \S 1-2$ determina: a) os pais, ou ao menos um deles ou quem legitimamente faz as suas vezes, consintam $\left(\S 1,1^{\circ}\right)$; b) haja fundada esperança de que será educada na religião católica; se essa esperança faltar de todo, o Batismo seja adiado segundo as prescrições do direito particular, avisando-se aos pais sobre o motivo $\left(\$ 1,2^{\circ}\right)$; c) em perigo de morte, a criança filha de pais católicos, e mesmo não-católicos, é licitamente batizada mesmo contra a vontade dos pais $(\S 2)$.

Ao receber este pedido, a Igreja tem o direito de exigir as condições necessárias, não porque esteja interessada em fechar as portas, mas para ter o mínimo de "garantias de que tal dom se possa desenvolver, mediante uma verdadeira educação na fé e na vida cristã, de modo que o sacramento atinja a sua total "verdade",44.

Em relação aos pais, o cânon especifica que o consentimento deve ser dado por ambos ou pelo menos um deles, ou por aqueles que legitimamente ocupam o seu lugar. Não se exige a fé dos pais, mas o seu consentimento para a administração do sacramento ao filho e, consequentemente sua educação:

A necessidade do consentimento paterno para que seja baptizada legitimamente uma criança que não está em perigo de morte, é uma exigência que dimana do Direito natural; como diz S. Tomás, o filho naturalmente é algo do pai e, enquanto não puder fazer uso do seu livre arbítrio, depende em tudo dele. Além disso, a celebração do baptismo à margem desta disposição teria como consequência expor a criança ao perigo de perder a fé quando chegasse

43 Cf. Jỗo Paulo II, Catecismo da Igreja Católica, 1752.

44 SACRA CONGREGATIO PRO DOCTRINA FIDEI, Instructio De Baptismo parvulorum, 28. 
ao uso da razão, por falta da devida educação religiosa no lar paterno ${ }^{45}$.

Quanto às garantias exigidas a quem formula a petição em nome do infante, deve-se julgar suficiente toda aquela promessa que ofereça uma esperança fundada quanto à educação cristã das crianças. Além de estabelecer um requisito relevante para a liceidade do sacramento, ao mesmo tempo, oferece uma ampla margem para a apreciação das circunstâncias que ocorrem em cada caso concreto ${ }^{46}$.

Essas garantias são dadas, normalmente, pelos pais, embora possam ser supridas de diversos modos: através da escolha dos padrinhos e madrinhas, de algum parente próximo, ou da comunidade cristã (catequistas, o sacerdote). Se as garantias oferecidas são suficientes, o sacerdote não poderá recusar-se a administrar sem demora o Batismo. Mas se as garantias são insuficientes será prudente adiá-10 ${ }^{47}$.

No tocante às crianças adotadas por pessoas homossexuais, quanto à primeira exigência, o único requisito explícito que pede o cânon é o consentimento de ao menos um dos responsáveis:

Ainda que a relação mencionada seja contrária aos ensinamentos da Igreja e sua união não possua nenhum tipo de reconhecimento eclesial, se pelo menos um dos parceiros der seu consentimento e solicitar o batismo [para a criança], se cumpriria o primeiro requisito do c. 686. Na realidade, a Igreja aplica um critério de bondade à criança, que não deve ser privada da graça pelo modo de vida daqueles que a adotaram ${ }^{48}$.

Assim, o consentimento deverá ser exigido, como na relação pais e filhos. Isso não significa um reconhecimento das uniões homoafetivas e, muito menos, da adoção legal por parte do Estado feita por

45 Cf. P. LOMBAdíA - J.I. ARrietA, ed., Código de Direito canónico, 669-670. Cf. Communicationes 6 (1974) 36; SACRA Congregatio PRO DOCTRINA FideI, Instructio De Baptismo parvulorum, 31.

47 Cf. SaCra CONGREgatio PRO DoCTRINA FiDeI, Instructio De Baptismo parvulorum, 30.

48 G.R. MiLlán, Orientaciones jurídico-pastorales, 7. 
aqueles que se encontram nesta união. Será válido e lícito batizar a criança sem o consentimento somente in periculo mortis (cf. 868 §2).

A respeito da segunda exigência, a Igreja, de fato, poderá assentir o Batismo se eles derem as garantias de que, uma vez batizada, a criança será educada na fé católica. Procura-se com esta disposição, proteger a fé sacramental da criança que necessita de instrução adequada para desenvolver-se.

Este discernimento corresponde, em primeiro lugar, ao pároco que deve fazê-lo sobre essa esperança que, embora seja mínima, deverá ter algum fundamento objetivo. Neste caso, o pároco os advertirá da responsabilidade assumida e fará todo o possível para criar as condições necessárias a uma frutuosa celebração do sacramento.

É razoável pensar, dado o tipo de união dos solicitantes, na impossibilidade de encontrar neles razão suficiente a garantir uma educação cristã à criança. Neste caso, um mínimo de esperança será fundado nos padrinhos, para os quais o legislador apresenta mais condições precisamente para tutelar os direitos da criança ou, se necessário, em outros membros da família ou da comunidade que possam ser verdadeiros transmissores da fé.

Contudo, esgotadas todas as possibilidades e se faltar de todo a fundada esperança de que a criança será educada na religião católica, a administração do sacramento seja adiada, explicando cuidadosamente aos responsáveis a falta de garantias e propondo uma nova via para superar o obstáculo, até que conste a mesma ${ }^{49}$.

\section{Conclusão}

A Igreja demonstrou ao longo de sua história, pela sua doutrina e pela sua prática, não conhecer outro meio senão o Batismo para assegurar às crianças a salvação eterna. Considerando alguns elementos (não estudados neste artigo: o mandato do Senhor, cf. $M t$ 28, 19; $M c$ 16, 15-16, a tradição imemorial da Igreja no Oriente e no Ocidente, a doutrina do pecado original de Agostinho e a capacidade que toda pessoa ainda não batizada tem para receber o Batismo, cf. can. 864),

49 Cf. G.R. Millán, Orientaciones jurídico-pastorales, 8. 
nota-se, de fato, que a Igreja está convencida da importância do Batismo e da necessidade de administrá-lo também às crianças.

Atualmente, o pedido para batizar crianças adotadas legalmente por pessoas do mesmo sexo tem interrogado, indubitavelmente, a ação pastoral da Igreja e tornado complexa a busca de uma atitude equilibrada e uma resposta concreta. Uma atitude respeitosa e não julgadora em relação às pessoas homossexuais não legitima suas condutas nem lhes dão o direito ao matrimônio e à adoção. Todavia, onde existir o reconhecimento legal de uniões homoafetivas e permissão para adotar crianças, caso solicitem o Batismo à criança que se encontra sob seus cuidados, a Igreja tem o dever de averiguar as condições reais em vista da transmissão da fé e do bem integral do infante no seio destas uniões.

Das razões apresentadas no texto, emergem duas orientações: primeiro, a reconfirmação da escolha de não privar os pequenos do Batismo, a Igreja insiste que se deve administrá-lo; segundo, a preocupação em assegurar a sua educação na fé católica. É evidente que esta resposta nem sempre será recebida de maneira contundente, pois haverá aqueles que o negarão. Recorda-se, portanto, uma vez mais "que a situação de vida [dos responsáveis] não é mais importante que a graça do Batismo e que a criança não tem nenhuma responsabilidade pelo estado de vida de quem pede para ela o sacramento" $" 50$.

Na realidade, o nó do problema está na educação cristã. Ciente da gratuidade do dom de Deus, a Igreja tem o direito de exigir as garantias mínimas para a educação na fé da criança e o acompanhamento necessário para que a Iniciação cristã seja completada e se garanta uma participação consciente e frutuosa no seio da Igreja. Não se trata de uma certeza absoluta, mas se julga suficiente toda aquela promessa que ofereça uma fundada esperança de que poderá existir tal educação.

Não é irrelevante favorecer o acesso da criança ao sacramento. Lembra-se, uma vez mais, que o Batismo é um direito de toda pessoa humana. Não obstante as dificuldades resultantes do atual contexto social, caracterizado pela instabilidade dos valores e pelos conflitos ideológicos, a Igreja permanece fiel ao mandato do Senhor.

50 CONFERÊNCIA NACIONAL DOS BISPOS DO BRASIL, Orientações pastorais e canônicas, 2. 


\section{Bibliografia}

\section{Códigos}

Codex Iuris Canonici Pii X Pontificis Maximi iussu digestus, Benedicti Papae XV auctoritate promulgatus, AAS 9/II (1917) 2-593.

Codex Iuris Canonici auctoritate Ioanni Pauli PP. II promulgatus, AAS 75/II (1983) I-XXX, 1-324.

Codex Canonum Ecclesiarum Orientalium auctoritate Ioanni Pauli PP. II promulgatus, AAS 82 (1990) I-XXX, 1034-1363.

LombadíA, P. - Arrieta, J.I., ed., Código de Direito Canónico, $2^{\mathrm{a}}$ ed., Braga: Diario do Minho, 1997.

Código de Direito Canônico. Com a legislação complementar da $C N B B, 12^{a}$ ed., São Paulo: Edições Loyola, 2013.

\section{Papas}

JoÃo Paulo II, Catecismo da Igreja Católica. Novíssima edição de acordo com o texto em latim, $4^{\mathrm{a}}$ ed., São Paulo: Loyola 2017.

IoAnNes Paulus II, Allocutio Ad Romanae Rotae praelatos auditores, 21 ian. 1999, AAS 91 (1999) 622-627.

FRANCISCUS, Adhortatio Apostolica Evangelii Gaudium, 24 nov. 2013, AAS 105 (2013) 1019-1137.

Adhortatio Apostolica Post-Synodalis Amoris Laetitia, 19 mar. 2016, AAS 108 (2016) 311-446. 


\section{Concílios, Congregações, Conselhos, Conferências}

Sacrosantum Concilium Oecumenicum Vaticanum II, Constitutio dogmatica de Ecclesia Lumen Gentium, 21 dec. 1964, AAS 57 (1965) 5-75.

CONGREGAÇÃO PARA A EdUCAÇÃO CATÓliCA, Homem e mulher os criou. Para uma via de diálogo sobre a questão do gender na educação, Coleção Documento da Igreja 51, São Paulo: Paulinas, 2019.

Sacra Congregatio Pro Doctrina FideI, Instructio De Baptismo parvulorum, 20 oct. 1980, AAS 72 (1980) 1137-1156.

CONGREgAtio PRo Doctrina FIDEI, Epistola Ad universos catholicae Ecclesiae episcopos de pastorali personarum homosexualium cura, 1 oct. 1986, AAS 79 (1987) 543-554.

- Instructio De observantia erga vitam humanam nascentem deque procreationis dignitate tuenda, 22 feb. 1987, AAS 80 (1988) 70102.

- De contubernalibus eiusdem sexus quoad consectaria contubernii, 3 iun. 2003, AAS 96 (2004), 41-49.

PONTIFICIA COMMISSIO CODICI IURIS CANONICI RECOGNOSCENDO, «Acta Commissionis», Communicationes 6 (1974) 29-59.

Pontifício Conselho «Justiça e PAZ», Compêndio da Doutrina Social da Igreja, São Paulo: Paulinas, 2005.

PONTIFÍCIO CONSElHO PARA A FAMÍlIA, Família, matrimônio e uniões de fato, Documentos Vaticanos, Città del Vaticano: Libreria Editrice Vaticana, 2000.

— Sexualidade humana. Verdade e significado, $5^{\mathrm{a}}$ ed., São Paulo: Paulinas, 2006.

SíNODO DOS BISPOS, Instrumentum laboris. Os desafios pastorais da família no contexto da evangelização, São Paulo: Paulinas, 2014. 
CONFERÊNCIA NACIONAL DOS BISPOS DO BRASIL, Orientações pastorais e canônicas sobre o Batismo de crianças, filhas ou adotadas, por pessoas em união homossexual, Brasília: [S.n.], 2016.

United States Conference of CATHOliC Bishops, Ministerio a las personas con inclinación homosexual. Directrices para la atención pastoral, Washington: [S.n.], 2007.

\section{Livros e artigos}

Bíblia de Jerusalém, São Paulo: Paulus, 2001.

Blanco, M., «Comentario al can. 489». In: Á. MARZOA - J. MiRAS R. Rodríguez-Ocaña, ed., Comentario exegético al Código de Derecho canónico, III/1, $3^{\mathrm{a}}$ ed., Navarra: EUNSA, 2002, 447-451.

—, «Comentario al can. 867». In: Á. MARZOA - J. MIRAS - R. Rodríguez-OCAÑA, ed., Comentario exegético al Código de Derecho canónico, III/1, $3^{\mathrm{a}}$ ed., Navarra: EUNSA, 484-486.

DinIz, M.H., Curso de Direito civil brasileiro. Direito de Família, 5, $28^{\text {a }}$ ed., São Paulo: Saraiva, 2013.

FALCÃo DE BARROS, J.F., Os sacramentos da Iniciação cristã administrados aos adotados por pessoas do mesmo sexo que vivem em união estável. [S.i]; [S.n].

Hagan, J., «Novos modelos de família». In: Pontifício Conselho PARA A FAMÍLIA, Lexicon. Termos ambíguos e discutidos sobre familia, vida e questões éticas, Brasília: CNBB, 2007, 745-749.

Millán, G.R., Orientaciones jurídico-pastorales sobre la admisión al Bautismo de los hijos, biológicos o adoptados, de parejas homosexuales. Diócesis de Osma-Soria.

OTADUY, J., «Comentario al can. 22». In: Á. MARZOA - J. MIRAS - R. RodrígueZ-OCAÑA, ed., Comentario exegético al Código de Derecho canónico, I, $3^{\mathrm{a}}$ ed., Navarra: EUNSA, 411-416. 
Polaino-Lorente, A., «"Matrimônio” de homossexuais», in PonTIFÍ́CIO CONSELHO PARA A FAMÍLIA, Lexicon. Termos ambíguos e discutidos sobre família, vida e questões éticas, Brasília: CNBB, 2007, 609-621.

Ritual do Batismo de crianças. Ritual Romano. Renovado por decreto do Concílio Vaticano II, promulgado por autoridade do Papa Paulo VI, São Paulo: Paulus, 2003.

SAN José PRISCO, J., Derecho parroquial. Guía canónica y pastoral, Salamanca: Ediciones Sígueme, 2008.

Sousa E SiLva, M.F., Direito Sacramental, 1, Lisboa: Universidade Católica Editora, 2004.

VAlle, J.N., «Adopción». In: J. OtAduY - A. VianA - J. SedAnO, ed., Diccionario general de Derecho canónico. A iure - celibato, I, Navarra: Thomson Reuters Aranzadi, 2012, 252-256. 